Pontifícia Universidade Católica $_{\text {a }}$ DO RIO DE JANEIRO

Paula da Assunção Azevedo Silva

\title{
A (RE)CONSTRUÇÃO DO SIGNIFICADO DA (IN)CIVILIDADE NO AMBIENTE DE TRABALHO ATRAVÉS DE EXPLICAÇÕES
}

Dissertação de Mestrado

Dissertação apresentada ao Programa de PósGraduação do Departamento de Letras da Pontifícia Universidade Católica do Rio de Janeiro como requisito parcial para obtenção do título de Mestre em Letras.

Orientadora: Profa. Maria do Carmo Leite de Oliveira 
Pontifícia Universidade Católica $_{\text {a }}$

Paula da Assunção Azevedo Silva

\section{A (RE)CONSTRUÇÃO DO SIGNIFICADO DA (IN)CIVILIDADE NO AMBIENTE DE TRABALHO ATRAVÉS DE EXPLICAÇÕES}

Dissertação apresentada como requisito parcial para obtenção do grau de Mestre pelo programa de PósGraduação em Letras do Departamento de Letras do Centro de Teologia e Ciências Humanas da PUCRio. Aprovada pela Comissão Examinadora abaixo assinada.

Profa. Maria do Carmo Leite de Oliveira

Orientadora

Departamento de Letras - PUC-Rio

Profa. Maria das Graças Dias Pereira

Departamento de Letras - PUC-Rio

Profa. Sonia Bittencourt Silveira

UFJF

Profa. Denise Berruezo Portinari Coordenadora Setorial do Centro de Teologia

e Ciências Humanas - PUC-Rio

Rio de Janeiro, 12 de abril de 2012. 
Todos os direitos reservados. É proibida a reprodução total ou parcial do trabalho sem autorização da universidade, da autora e da orientadora.

\section{Paula da Assunção Azevedo Silva}

Graduou-se em Letras pela Universidade do Estado do Rio de Janeiro, com habilitação em Inglês e Literaturas de Língua Inglesa, em 2009. Trabalhou como professora de língua inglesa e revisora linguística. Atualmente, é assistente de Direção de Conteúdo em uma empresa privada. Áreas de interesse: Comportamento Organizacional. Área de pesquisa: Pragmática; Linguística Aplicada.

Ficha Catalográfica

Silva, Paula da Assunção Azevedo

A (re)construção do significado da (in)civilidade no ambiente de trabalhop através de explicações / Paula da Assunção Azevedo Silva ; orientadora: Maria do Carmo Leite de Oliveira. - 2012.

$110 \mathrm{f}$; $30 \mathrm{~cm}$

Dissertação (mestrado)-Pontifícia Universidade Católica do Rio de Janeiro, Departamento de Letras, 2012.

Inclui bibliografia

1. Letras - Teses. 2. (In)civilidade. 3. Normas de convivência. 4. Ambiente de trabalho. 5. Comportamento organizacional. 6. Explicações (accounts). I. Oliveira, Maria do Carmo Leite de. II. Pontifícia Universidade Católica do Rio de Janeiro. Departamento de Letras. III. Título. 
Para Cris, meu "vidão", homem aventureiro, generoso e apaixonado, pesquisador brilhante e inspirador. Você tornou isto possível. 


\title{
Agradecimentos
}

A Deus, por ter colocado o Mestrado da PUC-Rio na minha história e ter permitido que, no seu decorrer, eu conhecesse pessoas que eu sei que jamais sairão da minha vida.

Aos meus pais, por tudo. Simplesmente por serem quem eles são e me apoiarem incondicionalmente nas minhas escolhas, sejam elas quais forem. Obrigada por confiarem tanto em mim e se preocuparem tanto com a minha felicidade.

À Linguística, por ter me fascinado, me desafiado, me instigado e me ensinado a ter disciplina, resignação e força de vontade.

À PUC-Rio, à Capes e à Faperj, pelos auxílios concedidos, sem os quais este trabalho não poderia ter sido realizado.

À Marina R. A. Augusto, pela profissional e mulher sem igual que é, mas ainda mais pelas vezes em que foi minha amiga, mãe e conselheira. Obrigada por ter compreendido minhas escolhas.

\begin{abstract}
À Maria do Carmo L. de Oliveira, por ter aceitado ser minha orientadora e me ensinado não só regras indispensáveis de polidez, mas também a ter mais autonomia, independência e fé.

À Lulu e Juju, por dividirem comigo suas ansiedades, pelas horas e horas de desabafos, pela companhia imprescindível naquela noite que viramos juntas terminando na última hora um trabalho final no nosso primeiro período. Acima de tudo, pela amizade, que será eterna.
\end{abstract}


À Andréa Cherman, à Patrícia Tomei, aos mestrandos da disciplina de Comportamento Organizacional do IAG, à Luciana Oliveira e à Carla Leite, por terem sido peças chave em etapas cruciais da minha pesquisa.

Aos funcionários do departamento de Letras da PUC-Rio, pela paciência e pelo apoio ao longo do curso.

Aos professores e colegas que me acompanharam na trajetória do Mestrado. 


\section{Resumo}

Silva, Paula da Assunção Azevedo; Oliveira, Maria do Carmo Leite de. A (Re)Construção do Significado da (In)Civilidade no Ambiente de Trabalho através de Explicações. Rio de Janeiro, 2012. 110p. Dissertação de mestrado- Departamento de Letras, Pontifícia Universidade Católica do Rio de Janeiro.

O presente estudo tem por objetivo investigar a questão da (in)civilidade no ambiente de trabalho a partir da análise das explicações utilizadas na fala de profissionais de diferentes organizações empresariais. O corpus foi constituído por entrevistas individuais semiestruturadas realizadas com cinco estudantes do curso de Mestrado em Administração do IAG da PUC-Rio e cujas experiências profissionais diferem quanto ao tempo de trabalho, à área de atuação e ao tipo de organização em que atuam ou atuaram. À luz da teoria sobre accounts (ArribasAyllon, Sarangi \& Clarke, 2011; Buttny \& Morris, 2001; Mätikalo, 2003; Raevare, 2010), averiguou-se o modo como os entrevistados (re)constroem os significados da (in)civilidade por meio de explicações referentes a suas manifestações, sua importância e fatores que a (des)favorecem no ambiente organizacional. Os resultados apontam não só para uma dificuldade dos entrevistados em circunscrever o significado da (in)civilidade, como também evidenciam sua crença de que certas normas de civilidade são passíveis de serem suspensas em determinados contextos de trabalho.

\section{Palavras-chave}

(In)civilidade; normas de convivência; ambiente de trabalho; comportamento organizacional; explicações (accounts). 


\section{Abstract}

Silva, Paula da Assunção Azevedo; Oliveira, Maria do Carmo Leite de. The (Re)Construction of (In)civility's Meaning in the Workplace through Accounts. Rio de Janeiro, 2012. 110p. MSc. Dissertation - Departamento de Letras, Pontifícia Universidade Católica do Rio de Janeiro.

The present study aims to investigate the issue of (in)civility in the workplace through the analysis of accounts used in the speech of professionals from different business organizations. The corpus consisted of individual semistructured interviews conducted with five MBA students from IAG (PUC-Rio) whose professional experiences differ in terms of working time, area of activity and the type of organization in which they work or have worked. In light of the theory on accounts (Arribas-Ayllon, Sarangi \& Clarke, 2011; Buttny \& Morris, 2001; Mätikalo, 2003; Raevare, 2010), this study examined the way interviewees (re)construct the meaning(s) of (in)civility by using accounts related to the its manifestations, its importance and the factors that encourage or discourage it in the workplace. The results indicate not only the interviewees' difficulty in circumscribing the meaning of (in)civility, but also reveal their belief that some civility-related rules may be disregarded in certain professional contexts.

\section{Keywords}

(In)civility; communal interaction rules; workplace; organizational behavior; accounts. 


\section{Sumário}

1. Introdução

2. A (in)civilidade 16

2.1. (In)civilidade e (im)polidez 16

2.2. (In)civilidade e sociabilidade 20

2.3. A (in)civilidade nos estudos organizacionais 26

3. A teoria dos accounts (explicações) 31

4. Abordagem metodológica 43

4.1. O paradigma qualitativo-interpretativista 43

4.2. A entrevista semiestruturada 46

4.3. Definição dos sujeitos de pesquisa 51

4.4. Geração dos dados 52

4.5. Contextualização dos participantes da pesquisa 56

4.6. Procedimentos de análise 58

5. Compreendendo a (in)civilidade no meio de trabalho 59

5.1. Os significados da (in)civilidade 59

5.2. As explicações sobre (in)civilidade 64

5.2.1.Explicações para visões da (in)civilidade: 64 manifestações

5.2.2. Explicações para a variação de normas de civilidade 69

5.2.2.1. Área de atuação 69

5.2.2.2. Tipo de papel profissional 71

5.2.2.3. Perfil ("idade") da empresa 72

5.2.2.4. Distância social entre chefe e subordinado 73 
5.2.3. Explicações para a importância da civilidade nas organizações

5.2.4. Explicações para a ocorrência de comportamentos (in)civilizados

5.2.4.1. Exemplo da liderança

5.2.4.2. Educação: socialização e escolaridade

5.2.4.3. Relações de poder: natureza pessoal 87

5.2.4.4. Relações de poder: natureza cultural 89

5.2.4.4.1. Cultura externa à organização 90

5.2.4.4.2. Cultura organizacional 92

6. Considerações Finais 97

7. Referências Bibliográficas

103

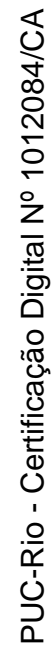

8. Anexo - Convenções de Transcrição 
Em todos os lugares, sempre foi e será necessário que existam modos de regulação das relações humanas em sociedade. O direito, e especialmente o contrato, é um dentre eles. Os costumes e, entre outros, a polidez são um outro crivo indispensável... A própria natureza não cessa de ser polida.

Regine Dhoquois 